OPEN ACCESS

Edited by:

Tom Crick,

Swansea University, United Kingdom

Reviewed by:

Suleiman Ibrahim Sharif, University of Sharjah,

United Arab Emirates

Nigel Francis,

Swansea University, United Kingdom

${ }^{*}$ Correspondence:

Vivian W. Y. Lee

vivianlee@cuhk.edu.hk

Specialty section:

This article was submitted to

Digital Education

a section of the journal

Frontiers in Education

Received: 08 December 2020

Accepted: 07 January 2021

Published: 14 April 2021

Citation:

Li JTS, Ng EEN and Lee WWY (2021)

The Use of Virtual Reality in Pharmacy

Education in Hong Kong: Lessons

Learnt. Front. Educ. 6:639126.

doi: 10.3389/feduc.2021.639126

\section{The Use of Virtual Reality in Pharmacy Education in Hong Kong: Lessons Learnt}

\author{
Joyce T. S. Li, Enoch E. N. Ng and Vivian W. Y. Lee* \\ Centre for Learning Enhancement and Research, The Chinese University of Hong Kong, Shatin, China
}

Virtual reality (VR) refers to an artificial environment which is experienced through sensory stimuli (such as sights and sounds) provided by a computer and in which one's actions partially determine what happens in the environment (Merriam-Webster.com Dictionary, Merriam-Webster, 2020). In recent years, VR is increasingly used in different fields, and its role in medical practice is expanding quickly (Darekar et al., 2015; Chirico et al., 2016). One important feature of VR technology is its reproducibility (Ramnanan and Pound, 2017; Cao and Cerfolio, 2019). Practitioners can rehearse a procedure on a virtual patient or simulated tissue as many times as they wish before performing it on real patients. In medical education, VR allows students to see through body tissues and visualize the underneath areas (Cao and Cerfolio, 2019; Yu et al., 2019; Siyar et al., 2020). Practice experience is an essential element in pharmacy education (Teramachi et al., 2018). It is effective in boosting students' communication skills and problem-solving skills, which are both crucial for the provision of patient-centered care in a team-based approach (Lang et al., 2019). Unfortunately, actual practice experience can be limited by various factors, such as the policies at attachment sites, patients' preference, and availability of teaching staff (Wartman, 2019; Shrestha et al., 2020). Therefore, institutions are looking for alternative channels for students to practice their skills. One strategy is to adopt simulated patient cases (Kurup et al., 2017; Willemsen-Dunlap et al., 2018; Silva et al., 2019). In this paper, we share our experience of using VR learning tools in pharmacy education in a Hong Kong university. We will discuss the opportunities, challenges, and suggestions for future development of VR in pharmacy education.

Keywords: pharmacy education, virtual reality, pedagogy, active learning, practice experience

\section{OUR EXPERIENCE OF USING VR IN UNDERGRADUATE PHARMACY EDUCATION}

The undergraduate pharmacy curriculum at the Chinese University of Hong Kong lasts for 4 years. During year 1 and 2, the pharmacy curriculum comprises of basic science courses as well as some basic pharmacy practice courses including introduction to pharmacy and principles of pharmaceutical dispensing. Students spend most of the time in the classroom to learn the pharmacology and therapeutic use of drugs, as well as in the laboratory to learn drug manufacturing technique in year 2 and 3. In the 4th year, students have clerkship training at clinical sites, where they need to assess patients' conditions and propose treatment plans for patients independently. Students need to complete four compulsory courses on pharmacology 
and therapeutics during university study, which cover the pharmacological management of gastrointestinal diseases, endocrine diseases, cardiovascular diseases, neuropsychiatric diseases, rheumatic diseases, infectious diseases, and some other diseases. After graduation, they will receive internship training at workplaces for 1 year before registration.

In order to better prepare students for their clinical year, we developed a few VR videos for year three pharmacy students to practice their patient assessment and counseling skills. The VR videos were used in the course "Pharmacology and Therapeutics II," which aimed to teach students pharmacology and therapeutics knowledge on cardiovascular diseases and endocrine diseases. A pilot test was done in 2017/2018 school year and the videos were used for teaching in 2018/2019 school year. There were around fifty students in each school year.

In the pilot test, we produced two immersive VR cases in cardiology on acute myocardial infarction and heart failure. The reason that we have chosen these 2 topics was because students voiced that they had difficulty understanding the topic well due to their complexity. The cases were modified from real patient cases in our teaching hospital. We hoped that using the VR technology with real patient cases could enhance the understandings of students. By using head-mounted devices, students played the role of hospital pharmacists and interacted with the patients, care-givers, and healthcare professionals in the cases. Students needed to interview patients and their care-givers to collect information and communicate with other healthcare professionals to refine the treatment plans. We collected students' feedback on the effectiveness of immersive VR cases on improving their disease knowledge, communication skills, and learning experience. In general, students found the VR cases intriguing and they appreciated our effort in producing the cases. Over $90 \%$ of students agreed that the VR cases were helpful for understanding the learning content and enhancing their problem-solving capability. They also gave constructive comments on the areas for improvement. Students pointed out that the best part of the VR cases was the ability to show patients' clinical symptoms clearly. However, setting up VR devices occupied extra class time, and they thought similar learning outcomes could be achieved by plain videos or photos instead.

In response to students' feedback, we modified our teaching plan in the subsequent school year. We produced three 360 degrees spherical videos on acute myocardial infarction, thromboembolic diseases, and heart failure for students to watch on their own before class. Students would still play the role of hospital pharmacists in the videos, but they did not need to wear VR headsets and the experience was less immersive. Students could click different icons on the screen to collect information on patient's vital signs, blood test results, $\mathrm{x}$-ray films, and medications. They should assess the treatment plans proposed and give relevant suggestions. Guiding questions were provided to help students identify the drug-related problems and design the treatment plans. Students discussed their proposed plans with their peers in class and teacher guided the discussion. We collected students' feedback on their learning experience and knowledge gain again in 2018/2019 school year. Using the 5-point Likert scale, students showed statistically significant improvement on their knowledge on all three topics (from $2.82 \pm 0.77$ to $3.58 \pm 1.00, p<0.01$ for heart failure, from $2.87 \pm 0.81$ to $3.46 \pm 1.03, p=0.04$ for acute myocardial infarction, and from $3.03 \pm 0.82$ to $3.55 \pm 0.97, p=0.04$ for thromboembolic disorders). They also showed statistically significant improvement on the ability (from $2.76 \pm 0.85$ to 3.36 $\pm 0.96, p=0.02$ ) and confidence (from $2.66 \pm 0.75$ to $3.27 \pm 0.94$, $p=0.01)$ to provide patient consultation. In general, students enjoyed using VR as a learning tool and they believed the training would be useful to their future practice.

\section{DISCUSSION}

From our experience, we identified the opportunities and challenges of using VR in pharmacy education. Virtual reality learning activities allowed students to experience patient cases which were impossible to generate in normal classroom environments. They were effective in enhancing students' knowledge on diseases and confidence on patient counseling. Third year pharmacy students had not started bedside learning. Over $75 \%$ of the surveyed students had never talked to a patient in hospital and over $90 \%$ of students had never talked to a physician on drug prescription before. They had limited experience on reading case notes, taking patients' history, or counseling patients. The VR exercises allowed students to practice and polish their skills before they entered the clinical year and internship.

The role of VR in medical education is emerging (Izard et al., 2017; Uppot et al., 2019). Virtual reality has been used in pharmacy education to teach students knowledge on anatomy, physiology, and pharmacology, and to train up students' compounding and dispensing technique (Ventola, 2019). It provides three-dimensional pictures on body structures and drug-receptor interactions to aid students' learning (Richardson et al., 2013). Virtual reality exercises enable students to gain practice experience that may be impractical or unethical in real healthcare settings. For example, the exercises allow students to make mistakes while showing them the consequences of making a wrong decision. They also allow each student to have firsthand experience of interviewing patients and talking to other healthcare professionals.

Nevertheless, such benefits may not be easy to achieve. Firstly, a VR case requires much longer production time and much high production cost than a pain video or a paper case. Secondly, technical problems may hinder students' learning experience. Extra class time is needed to set up the VR equipment in a normal classroom. If the classroom is not covered with stable network, it will take even more time for downloading the videos in class. Thus, the time for case discussion may be reduced. Watching VR videos in class consumes the power in students' mobile devices quickly, which can be un-user-friendly if hardware supports are inadequate. In addition, it is difficult to have enough headmounted devices for every student to do the immersive VR exercise at the same time. Extra administrative effort is needed for arranging the teaching timetable. These issues should be taken into consideration before producing a VR case and potential problems should be addressed before incorporating the VR case 
into the curriculum. With the growing use of technology in education, it is important for educational institutions to have a centralized support and vision to sustain the development of using various technologies in education.

Virtual reality has demonstrated potential in numerous healthcare fields, from disease diagnosis, patient assessment, acute treatment, to long-term rehabilitation (Freeman et al., 2017; Laver et al., 2017). The scope of VR application is expected to expand further. It is likely that students will come across VR technology at some point in their future practice. Therefore, it would be favorable for them get adapted to this new technology during university study. Under the ongoing impact of COVID-19 pandemic, many bedside teaching activities such as practicum, clerkship, and clinical attachment have been held (Ahmed et al., 2020). Teachers turn to alternative pedagogies, and simulation is one of those (Newman and Lattouf, 2020; Rajab et al., 2020). Although VR cases cannot replace actual practice experience, it can be used to build students' clinical knowledge when real patient contact should be avoided. Nonetheless, careful selection of teaching cases and modes of delivery are needed to achieve the learning outcomes.

In summary, there are two learning points that we would like to share. Firstly, decision to use VR tools in teaching should be made in accordance with the course objectives. It could be desirable for courses that emphasize on practical skills and experiential learning but may not be cost-effective when knowledge can be delivered in a straightforward manner. Secondly, technical issues should be considered before adopting VR technology in the curriculum. Hardware and software

\section{REFERENCES}

Ahmed, H., Allaf, M., and Elghazaly, H. (2020). COVID-19 and medical education. Lancet Infect. Dis. 20, 777-778. doi: 10.1016/S1473-3099(20) 30226-7

Cao, C., and Cerfolio, R. J. (2019). Virtual or augmented reality to enhance surgical education and surgical planning. Thorac. Surg. Clin. 29, 329-337. doi: 10.1016/j.thorsurg.2019.03.010

Chirico, A., Lucidi, F., De Laurentiis, M., Milanese, C., Napoli, A., and Giordano, A. (2016). Virtual reality in health system: beyond entertainment. A minireview on the efficacy of VR during cancer treatment. J. Cell Physiol. 231, 275-287. doi: 10.1002/jcp.25117

Darekar, A., McFadyen, B. J., Lamontagne, A., and Fung, J. (2015). Efficacy of virtual reality-based intervention on balance and mobility disorders post-stroke: a scoping review. J. Neuroeng. Rehabil. 12:46. doi: 10.1186/s12984-015-0035-3

Freeman, D., Reeve, S., Robinson, A., Ehlers, A., Clark, D., Spanlang, B., et al. (2017). Virtual reality in the assessment, understanding, and treatment of mental health disorders. Psychol. Med. 47, 2393-2400. doi: 10.1017/S003329171700040X

Izard, S. G., Juanes Méndez, J. A., and Palomera, P. R. (2017). Virtual reality educational tool for human anatomy. J. Med. Syst. 41:76. doi: 10.1007/s10916-017-0723-6

Kurup, V., Matei, V., and Ray, J. (2017). Role of in-situ simulation for training in healthcare: opportunities and challenges. Curr. Opin. Anaesthesiol. 30, 755-760. doi: 10.1097/ACO.0000000000000514

Lang, B., Zhang, L., Lin, Y., Han, L., Zhang, C., and Liu, Y. (2019). Team-based learning pedagogy enhances the quality of Chinese pharmacy support should be sufficient to ensure each student has a fair and enjoyable learning experience.

\section{DATA AVAILABILITY STATEMENT}

The datasets used and/or analyzed during the current study are available from the corresponding author on reasonable request.

\section{ETHICS STATEMENT}

This study has been approved by the Survey and Behavioural Research Ethics Committee of the Chinese University of Hong Kong. Reference number: SBRE-18-520. Students submitted their written informed consent before participating in this study.

\section{AUTHOR CONTRIBUTIONS}

JL analyzed data and wrote the article. EN arranged the logistics and prepared teaching materials. VL contributed to the study design and supervised the study. All authors contributed to the article and approved the submitted version.

\section{FUNDING}

This study was funded by Teaching Development and Language Enhancement Grant for 2016-19 Triennium from The Chinese University of Hong Kong. The funding body had no role in the design of the study and collection, analysis, and interpretation of data and in writing the manuscript. education: a systematic review and meta-analysis. BMC Med. Educ. 19:286. doi: 10.1186/s12909-019-1724-6

Laver, K. E., Lange, B., George, S., Deutsch, J. E., Saposnik, G., and Crotty, M. (2017). Virtual reality for stroke rehabilitation. Cochrane Database Syst. Rev. 11:CD008349. doi: 10.1002/14651858.CD008349.pub4

Merriam-Webster.com Dictionary, Merriam-Webster (2020). Virtual Reality. Available online at: https://www.merriam-webster.com/dictionary/virtual $\% 20$ reality (accessed November 4, 2020).

Newman, N. A., and Lattouf, O. M. (2020). Coalition for medical education-A call to action: a proposition to adapt clinical medical education to meet the needs of students and other healthcare learners during COVID-19. J. Cardiac. Surg. 35, 1174-1175. doi: 10.1111/jocs.14590

Rajab, M. H., Gazal, A. M., and Alkattan, K. (2020). Challenges to online medical education during the COVID-19 pandemic. Cureus 12:e8966. doi: 10.7759/cureus.8966

Ramnanan, C. J., and Pound, L. D. (2017). Advances in medical education and practice: student perceptions of the flipped classroom. Adv. Med. Educ. Pract. 8, 63-73. doi: 10.2147/AMEP.S109037

Richardson, A., Bracegirdle, L., McLachlan, S. I., and Chapman, S. R. (2013). Use of a three-dimensional virtual environment to teach drug-receptor interactions. Am. J. Pharm. Educ. 77:11. doi: 10.5688/ajpe77111

Shrestha, S., Shakya, D., and Palaian, S. (2020). Clinical pharmacy education and practice in Nepal: a glimpse into present challenges and potential solutions. Adv. Med. Educ. Pract. 11, 541-548. doi: 10.2147/AMEP.S257351

Silva, A. P. G. D., Rodriguez, J. E. R., Oliveira, M. C., Negreiros, R. M. A., and Cavalcante, L. P. (2019). The alternative model of silicone for experimental simulation of suture of living tissue in the teaching of surgical technique. Acta. Cir. Bras. 34:e201900410. doi: 10.1590/s0102-865020190040000010 
Siyar, S., Azarnoush, H., Rashidi, S., and Del Maestro, R. F. (2020). Tremor assessment during virtual reality brain tumor resection. J. Surg. Educ. 77, 643-651. doi: 10.1016/j.jsurg.2019.11.011

Teramachi, H., Ino, Y., Sugita, I., Nishio, Y., Yoshida, A., Hayashi, Y., et al. (2018). Evaluating communication skills after long-term practical training among Japanese pharmacy students. Curr. Pharm. Teach. Learn. 10, 446-452. doi: 10.1016/j.cptl.2017.12.006

Uppot, R. N., Laguna, B., McCarthy, C. J., De Novi, G., Phelps, A., Siegel, E., et al. (2019). Implementing virtual and augmented reality tools for radiology education and training, communication, and clinical care. Radiology 291, 570-580. doi: 10.1148/radiol.2019182210

Ventola, C. L. (2019). Virtual reality in pharmacy: opportunities for clinical, research, and educational applications. P T. 44, 267-276.

Wartman, S. A. (2019). The empirical challenge of 21 st-century medical education. Acad. Med. 94, 1412-1415. doi: 10.1097/ACM.0000000000002866

Willemsen-Dunlap, A. M., Binstadt, E. S., Nguyen, M. C., Elliott, N. C., Cheney, A. R., Stevens, R. H., et al. (2018). Alternative markers of performance in simulation: where we are and where we need to go. Acad. Emerg. Med. 25, 250-254. doi: 10.1111/acem.13321

Yu, X., Xie, Z., Yu, Y., Lee, J., Vazquez-Guardado, A., Luan, H., et al. (2019). Skinintegrated wireless haptic interfaces for virtual and augmented reality. Nature 575, 473-479. doi: 10.1038/s41586-019-1687-0

Conflict of Interest: The authors declare that the research was conducted in the absence of any commercial or financial relationships that could be construed as a potential conflict of interest.

Copyright (c) $2021 \mathrm{Li}, \mathrm{Ng}$ and Lee. This is an open-access article distributed under the terms of the Creative Commons Attribution License (CC BY). The use, distribution or reproduction in other forums is permitted, provided the original author(s) and the copyright owner(s) are credited and that the original publication in this journal is cited, in accordance with accepted academic practice. No use, distribution or reproduction is permitted which does not comply with these terms. 